\title{
Interpreting risk factors for truck crash severity on mountainous freeways in Jiangxi and Shaanxi, China
}

\author{
Yonggang Wang ${ }^{1 *}$ (D) Ye Luo ${ }^{1}$ and Fayu Chen ${ }^{2}$
}

\begin{abstract}
The occurrence and severity of truck crashes generally involve complex interactions among factors correlated to driver characteristics, vehicle attributes, roadway geometry and environment conditions. Thus, the elucidation of the significance of these potential contributory factors is critical when developing safety improvement countermeasures. To this end, data from a total of 1175 crashes involving at least one large truck and collected between 2010 and 2015 from two typical freeways in mountainous areas in Jiangxi and Shaanxi (China), were analyzed using a partial proportional odds model to determine the significant risk factors for injury severity of these crashes. Fourteen total explanatory variables, including the age of the driver, seatbelt status, number of vehicle involved, type of transport, freight conditions, brake system status, disregarding speed limit or not, following distance, horizontal roadway alignment, vertical roadway alignment, seasons, day of week, time of crash, and weather were found to significantly affect the severities of the truck crashes. In addition, old drivers, involvement of multiple vehicles, failure to wear seatbelts, overloading, speeding, brake failure and risky following behavior, curve section, seasons (summer, autumn and winter), nighttime period, and adverse weather conditions were also found to significantly increase the likelihood of injury and fatality crashes. Taken together, these findings may serve as a useful guide for developing legislation and technical countermeasures to ensure truck safety on freeways in mountainous regions, particularly in the context of a developing country.
\end{abstract}

Keywords: Truck crash, Mountainous freeways, Risk factor, Partial proportional odds model

\section{Introduction}

Over the past two decades, China has experienced a dramatic increase in the use of large trucks - from about 11.3 million in 2007 to more than 21.7 million in 2016, i.e., a $92 \%$ increase, a large majority of which are used for long-distance commercial transport, according to China Statistical Yearbook - 2017. Likewise, the number of road crashes involving large trucks has also increased, and it has been reported that large trucks caused about $17.5 \%$ of total road motor vehicle crashes as well as $22 \%$ of total deaths annually in China, even though they account for only $7.8 \%$ of all registered motor vehicles [1]. In the UK, fatal road crashes involving heavy trucks, in per 100 million vehicle kilometers travelled, were

\footnotetext{
* Correspondence: wangyg@chd.edu.cn

${ }^{1}$ School of Highway, Chang'an University, P.O.Box 487, Middle Section of

South 2 Ring Rd., Xi'an 710064, Shaanxi, China

Full list of author information is available at the end of the article
}

approximately double those for passenger cars [2]. Given the human, social and economic costs, and the consequences of large truck crashes worldwide, it is thus necessary to determine the potential risk factors associated with these crashes in order to better understand how they occur and then establish suitable countermeasures.

Considerable research efforts have been devoted to investigate demographic characteristics of truck drivers, such as age, sex, driving experience, educational background, etc., in order to determine their relationship with the occurrence of crashes [1,3-5]. Several recent studies have focused on the multiple occupation-related factors of truck drivers, particularly those who are frequently involved in long-distance transport under the extremely stressful conditions, including commercial transport [1,3], license status [1,3-5], continuous driving hours [6], shift patterns [7], rest-break duration [8], and overloading or improper loading [1, 3, 4], etc., which 
may directly or partially affect the probability of being involved in a crash. Additionally, truck drivers' risky driving behaviors, such as speeding [1, 3, 4, 6, 9-14], failure to wear a seatbelt $[1,3,4,15]$, following too closely $[1,3,4,10,14]$, improper overtaking or lane changing $[4,10,15,16]$, inattention $[10,14]$, alcohol impaired driving $[1,3,4,6,10,12,17]$, and fatigue driving $[1,10,12,14,16]$, etc., have also been identified to have significant influence on the occurrence and injury severity of truck crashes. However, there is considerable difference in contributory variables between urban and rural areas $[11,16]$.

In addition, besides driver attributes, there are a wealth of factors associated truck crashes, such as vehicle attributes, road geometry and environment conditions [1, 3-6, 9-16]. Analysis of 10-year crash data collected between 1991 and 2000 from rural highways in Illinois (USA) showed that vehicle type and condition, roadway characteristics and conditions (e.g., sharp curve, steep grade, wet road surface, wide lane, wide/unprotected/painted median), environment conditions (e.g., fog/smoke/haze, severe cross wind, darkness light condition, rush hour, wet road surface) and accident characteristics had significant impact on the injury severities of truck drivers involved traffic accidents [13]. In another modeling study, speed limit and location type contributed significantly only to the frequency of truck crashes, while lighting status and terrain type were significant predictors of the severity outcome of such crashes [15]. After the analysis of 1787 truck crashes in Tennessee (USA), certain variables, such as posted speed limits, annual average daily traffic (AADT), lane width, degree of horizontal curvature, terrain type, median type, right side shoulder width, etc., were found to have significant effects on the likelihood of such crash occurrences [18]. Additionally, collision partner(s), existence of tunnels and bridges were also identified to be significantly correlated with the truck crash occurrence $[1,4,5,11,12$, 19].

In recent years, the logit-based and ordered probability regression models have often been applied to analyze the injury severity of truck-involved crashes $[1,4,6,9,11$, $12,14-16,19]$. However, these approaches assume that the effect of each parameter remains constant across all observations, which indicates that these approaches cannot capture the potential correlation between truck crash severity outcomes and unobserved effects related to driver, vehicle, roadway, and environment conditions at the time of the crash. Therefore, using the reported truck crash data from two typical freeways mountainous regions in Jiangxi and Shaanxi (China) over a recent 6-year time period, the primary purpose of this study is to quantify the potential risk factors using a partial proportional odds (PPO) model with logit function, which does not impose the parallel-lines assumption and allows one or more parameters to differ across an equation, while others remain the same for all equations $[3,5]$, so as to determine i) the risk factors contributing to the severity of truck crashes on mountainous freeways, and ii) the marginal effects of each explanatory factor. We anticipate that the findings reported here can be used to guide the development of legislations and technical countermeasures for truck safety on freeways in mountainous regions.

\section{Data}

A total of 5194 police-reported traffic crashes between 2010 and 2015 involving either personal injury/fatality or more than $¥ 1000$ property damage were originally selected from two freeway segments in mountainous areas in Jiangxi and Shaanxi (China), as shown in Fig. 1. Among these crash records, 1175 cases (22.62\%) involved at least one large truck and thus were included in the final database. Driver privacy was protected by anonymizing the data.

A three-point ordinal scale was used to classify the severity of truck crashes, including a. $1=$ PDO (property damage only): there is no less than $¥ 1000$ damage of road facilities and vehicles or negligible personal injuries; b. 2 =injury: there is at least one person injured requiring medical treatment after the crash but no person is killed; c. $3=$ fatality: there is at least one person killed immediately or dying within 30 days as a result of the crash. The distribution of the crash severity levels was as follows: $\mathrm{PDO}=$ $53.53 \%$, injury $=32.85 \%$ and fatality $=13.62 \%$.

The crash database constructed with information from the original police accident reports contains the additional information associated with the driver characteristics, vehicle attributes, and environment conditions, as shown in Table 1, in which driver characteristics include sex, age (young = younger than 30 years old; adult $=30$ 50 years old; and old $=$ older than 50 years old), and seat belt use; vehicle attributes include number of vehicles involved, type of transport, conditions of freight transport, status of brake system, disregard of speed limits or not, and following distance; and environment conditions include seasons (spring = March to May; summer = June to August; autumn = September to November; winter = December to February), day of week (weekends / holidays $=17: 00$ Friday to 24:00 Sunday and public holidays in China; working days $=0: 00$ Monday to 16:59 Friday), time of crash (daytime $=6: 00 \sim 18: 00$; nighttime $=$ evening 18:00 24:00 and night 24:00 6:00), weather (fine = sunny and cloudy; adverse = rainy, snowy and foggy).

Additionally, the database also contains the roadway horizontal (straight and curve) and vertical (level, upgrade, and downgrade) alignments, as shown in Table 1 , 


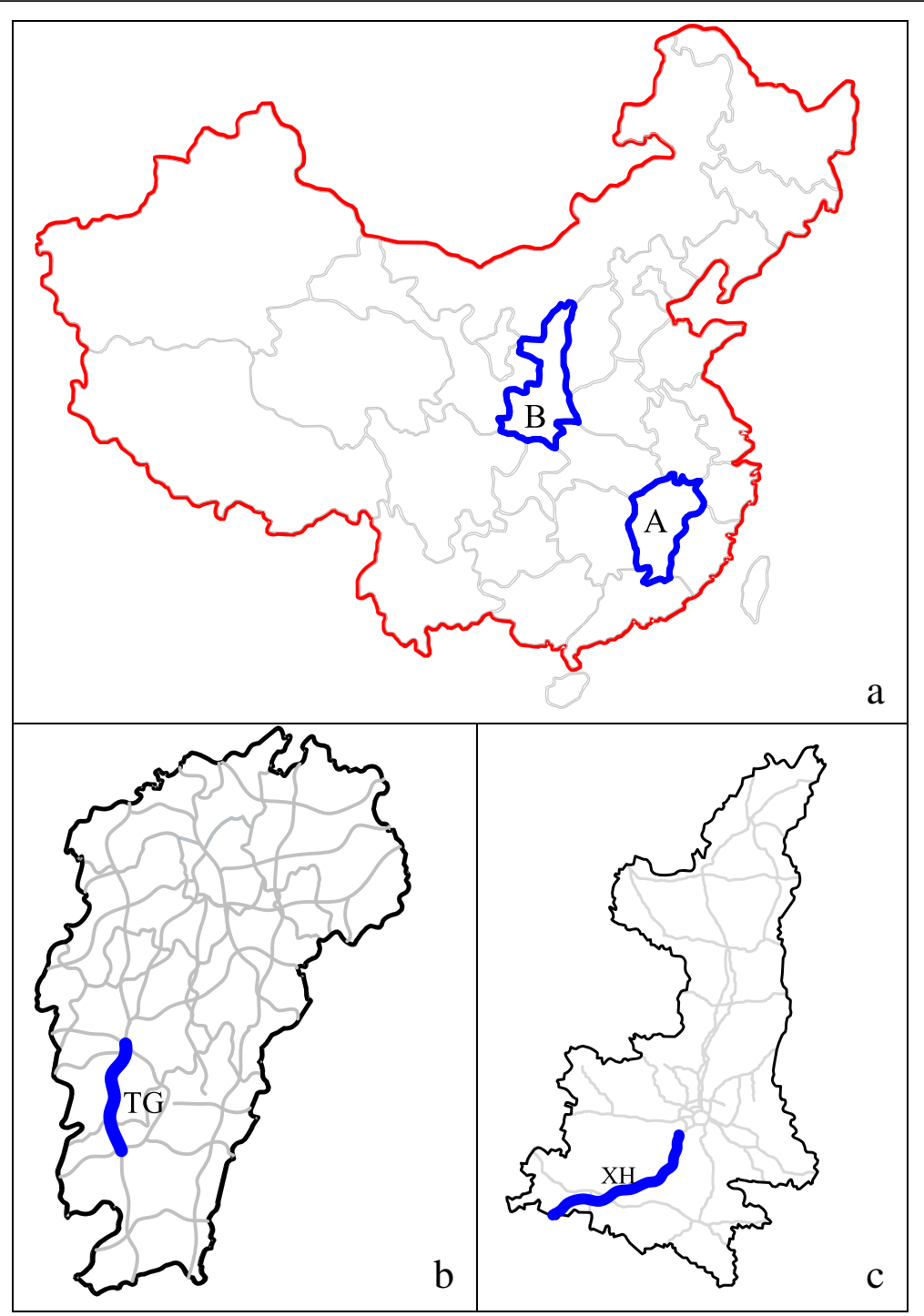

Fig. 1 Two mountainous freeway segments in Jiangxi and Shaanxi, China. a location of Jiangxi (A) and Shaanxi (B) in China mainland; b TG Freeway: a segment of Daguang Freeway G45 from Taihe Hub to Ganzhou Hub (K2916 + 390 K3044 + 169) in Jiangxi, China; c XH Freeway: a segment of Jingkun Freeway G5 from Hechizhai Interchange to Qipanguan Tunnel (K1102+608 K1463 + 451) in Shaanxi, China

which were extracted from the Google Earth map. Here, when the crash occurred while the vehicle was travelling uphill or downhill along a grade segment, then the contributory factor correlated with the roadway vertical alignment was considered as upgrade or downgrade, respectively. Otherwise, it was considered as level.

\section{Methodology}

As stated in the literature, the dependent variable (truck crash severity) used in this study represents an ordered outcome (e.g., PDO, injury and fatality), and therefore the ordered-response model was suitable for the analysis of such ordinal data.

Let $j$ was the crash severity level $(1=$ PDO; $2=$ injury; $3=$ fatality), thus the probability of crash $i$ having a severity level $j$ could be specified through a conventional ordered logit or proportional odds (PO) model on a set of $n$ independent explanatory variables [5] as follows:

$$
P\left(Y_{i}>j\right)=\frac{\exp \left(X_{i}^{\prime} \beta-\alpha_{j}\right)}{1+\exp \left(X_{i}^{\prime} \beta-\alpha_{j}\right)}, j=1,2,3
$$

where $X_{i}$ was a $n \times 1$ vector of explanatory variables for crash observation $i, \beta$ was a $n \times 1$ vector of parameter estimations, and $\alpha_{j}$ was a cut-off point for the $j$ th cut-off threshold in the model.

Clearly, the underdetermined parameter estimate $\beta$ was assumed to remain constant across each severity level for each variable, which was called parallel regression or proportional odds assumption. According to 
Table 1 Description of explanatory variables

\begin{tabular}{|c|c|c|c|c|c|c|c|}
\hline \multirow[t]{2}{*}{ Explanatory Variable } & \multicolumn{2}{|l|}{ PDO } & \multicolumn{2}{|c|}{ Injury } & \multicolumn{2}{|c|}{ Fatality } & \multirow{2}{*}{$\begin{array}{l}\text { Total } \\
\mathrm{N}\end{array}$} \\
\hline & $\mathrm{N}$ & $\%$ & $\mathrm{~N}$ & $\%$ & $\mathrm{~N}$ & $\%$ & \\
\hline Total Crash & 629 & 53.53 & 386 & 32.85 & 160 & 13.62 & 1175 \\
\hline \multicolumn{8}{|l|}{ Driver characteristics } \\
\hline \multicolumn{8}{|l|}{ Gender } \\
\hline Female $^{a}$ & 22 & 1.87 & 34 & 2.89 & 18 & 1.53 & 74 \\
\hline Male & 607 & 51.66 & 352 & 29.96 & 142 & 12.09 & 1101 \\
\hline \multicolumn{8}{|l|}{ Age } \\
\hline Young $(<30 \text { years })^{a}$ & 120 & 10.21 & 59 & 5.02 & 24 & 2.04 & 203 \\
\hline Adult (30 50 years) & 440 & 37.45 & 253 & 21.53 & 99 & 8.43 & 792 \\
\hline Old (> 50 years) & 69 & 5.87 & 74 & 6.30 & 37 & 3.15 & 180 \\
\hline \multicolumn{8}{|l|}{ Seatbelt status } \\
\hline Used $^{a}$ & 531 & 45.19 & 212 & 18.04 & 67 & 5.70 & 810 \\
\hline Not used & 98 & 8.34 & 174 & 14.81 & 93 & 7.91 & 365 \\
\hline
\end{tabular}

Vehicle attributes

Number of vehicle involved

\begin{tabular}{|c|c|c|c|c|c|c|}
\hline Single $e^{a}$ & 244 & 20.76 & 89 & 7.57 & 43 & 3.66 \\
\hline Multiple & 385 & 32.77 & 297 & 25.28 & 117 & 9.96 \\
\hline
\end{tabular}

Type of vehicle

Commercial transport $\begin{array}{llllllll}629 & 53.53 & 355 & 30.21 & 139 & 11.83 & 1123\end{array}$

Others $^{\mathrm{a}}$

$\begin{array}{lllllll}0 & 0 & 31 & 2.64 & 21 & 1.79 & 52\end{array}$

Conditions of freight

$\begin{array}{llllllll}\text { Not overloading a }^{\mathrm{a}} & 531 & 45.19 & 151 & 12.85 & 3 & 0.26 & 685\end{array}$

$\begin{array}{llllllll}\text { Overloading } & 98 & 8.34 & 235 & 20.00 & 157 & 13.36 & 490\end{array}$

Brake system

Not failed ${ }^{\mathrm{a}}$

Failed

Roadway speed limit

Regarding ${ }^{a}$

Disregarding

Following distance

Safe ${ }^{a}$

Unsafe

Road geometrics

Horizontal alignment

Straight ${ }^{\mathrm{a}}$

Curve

$\begin{array}{lllllll}384 & 32.68 & 143 & 12.17 & 33 & 2.81 & 560\end{array}$

$\begin{array}{lllllll}245 & 20.85 & 243 & 20.68 & 127 & 10.81 & 615\end{array}$

$\begin{array}{lllllll}511 & 43.49 & 152 & 12.94 & 7 & 0.60 & 670\end{array}$

$\begin{array}{lllllll}118 & 10.04 & 234 & 19.91 & 153 & 13.02 & 505\end{array}$

$\begin{array}{lllllll}388 & 33.02 & 83 & 7.06 & 18 & 1.53 & 489\end{array}$

$\begin{array}{lllllll}241 & 20.51 & 303 & 25.79 & 142 & 12.09 & 686\end{array}$

Vertical alignment

Level $^{\mathrm{a}}$

Upgrade

Downgrade

Environmental conditions

Season

Spring $^{a}$

Summer $\begin{array}{lllllll}332 & 28.25 & 153 & 13.02 & 15 & 1.28 & 500\end{array}$

$\begin{array}{lllllll}297 & 25.28 & 233 & 19.83 & 145 & 12.34 & 675\end{array}$

$\begin{array}{lllllll}99 & 8.42 & 102 & 8.68 & 55 & 4.68 & 256\end{array}$

$\begin{array}{lllllll}43 & 3.66 & 36 & 3.06 & 18 & 1.53 & 97\end{array}$

$\begin{array}{lllllll}487 & 41.45 & 248 & 21.11 & 87 & 7.41 & 822\end{array}$

Table 1 Description of explanatory variables (Continued)

\begin{tabular}{|c|c|c|c|c|c|c|c|}
\hline \multirow[t]{2}{*}{ Explanatory Variable } & \multicolumn{2}{|c|}{ PDO } & \multicolumn{2}{|c|}{ Injury } & \multicolumn{2}{|c|}{ Fatality } & \multirow{2}{*}{$\begin{array}{l}\text { Total } \\
\mathrm{N}\end{array}$} \\
\hline & N & $\%$ & $\mathrm{~N}$ & $\%$ & N & $\%$ & \\
\hline Autumn & 189 & 16.08 & 18 & 1.53 & 8 & 0.68 & 215 \\
\hline Winter & 133 & 11.32 & 198 & 16.85 & 127 & 10.81 & 458 \\
\hline \multicolumn{8}{|l|}{ Day of week } \\
\hline Weekends/holidays ${ }^{a}$ & 157 & 13.36 & 138 & 11.74 & 46 & 3.92 & 341 \\
\hline Weekday & 472 & 40.17 & 248 & 21.11 & 114 & 9.70 & 834 \\
\hline \multicolumn{8}{|l|}{ Time of crash } \\
\hline Daytime $^{a}$ & 538 & 45.79 & 205 & 17.45 & 19 & 1.62 & 762 \\
\hline Nighttime & 91 & 7.74 & 181 & 15.40 & 141 & 12.00 & 413 \\
\hline \multicolumn{8}{|l|}{ Weather } \\
\hline Fine $^{a}$ & 552 & 46.98 & 205 & 17.45 & 13 & 1.11 & 770 \\
\hline Adverse & 77 & 6.55 & 181 & 15.40 & 147 & 12.51 & 405 \\
\hline
\end{tabular}

Reference category

such assumption, each variable in the model may either increase or decrease the probability of higher crash severities, but this assumption was often violated in real applications.

Since the parallel-lines assumption may be violated only by one or a few independent variables, a random-effects generalized ordered logit model, also known as the gamma parameterization of the PPO model with logit function, which could be formulated $[3,5]$ as follows:

$$
\begin{aligned}
P\left(Y_{i}>j\right) & =\frac{\exp \left(X_{1 i}^{\prime} \beta_{1}+X_{2 i}^{\prime} \beta_{2}-\alpha_{j}\right)}{1+\exp \left(X_{1 i}^{\prime} \beta_{1}+X_{2 i}^{\prime} \beta_{2}-\alpha_{j}\right)}, j \\
& =1,2,3
\end{aligned}
$$

where the coefficient vector $\beta_{1}$, correlated with the independent explanatory variables $X_{1 j}$, was constant across all equations, and the coefficient vector $\beta_{2}$, related to other variables $X_{2 i}(m \times 1, m \leq n)$ violating the proportional odds assumption, differed across some severity level $j$. The parameters $\beta_{1}, \beta_{2}$ and $\alpha_{j}$ could be estimated via a user-written program (gologit2) in the Stata 14 software $[3,20]$ (StataCorp LLC., College Station, USA).

\section{Results}

The PPO model was implemented to analyze the effects of the explanatory variables listed in Table 1 using the user-written Stata package gologit 2, where $p<0.05$ was considered as the level for statistical significance of the explanatory variables. Specifically, the parallel-lines assumption for each variable was tested by the Wald tests to examine whether its coefficients differ across equations for the PPO model. Ultimately, the best fit model was presented in Table 2 (Pseudo $R^{2}=0.636$ ).

The estimated PPO model had one $\beta_{1}$ coefficient for each variable, one $\beta_{2}$ coefficient for the variables violating 
Table 2 Estimation results for the partial proportional odds model

\begin{tabular}{|c|c|c|c|c|}
\hline Varbiables & Definition & Est. & St.Err & $p$ \\
\hline \multicolumn{5}{|l|}{$\beta_{1}$} \\
\hline \multirow[t]{5}{*}{ Driver characteristics } & Male & - & - & n.s. \\
\hline & Age & & & \\
\hline & Adult (30 50 years) & - & - & n.s. \\
\hline & Old (> 50 years) & 0.844 & 0.319 & 0.008 \\
\hline & Failure to wear a seatbelt & 1.664 & 0.266 & $<0.001$ \\
\hline \multirow[t]{6}{*}{ Vehicle attibutes } & Multiple vehicles involved & 0.988 & 0.251 & $<0.001$ \\
\hline & Commercial transport & -1.921 & 0.513 & $<0.001$ \\
\hline & Overloading & 2.089 & 0.240 & $<0.001$ \\
\hline & Brake Failure & 0.687 & 0.274 & 0.012 \\
\hline & Disregarding speed limit & 1.436 & 0.239 & $<0.001$ \\
\hline & Unsafe following distance & 1.433 & 0.236 & $<0.001$ \\
\hline \multirow[t]{4}{*}{ Road geometrics } & Curve & 0.619 & 0.226 & 0.006 \\
\hline & Vertical alignment & & & \\
\hline & Upgrade & - & - & n.s. \\
\hline & Downgrade & -2.230 & 0.312 & $<0.001$ \\
\hline \multirow[t]{7}{*}{ Environmental conditions } & Season & & & \\
\hline & Summer & 1.453 & 0.320 & $<0.001$ \\
\hline & Autumn & -0.966 & 0.418 & 0.021 \\
\hline & Winter & 1.596 & 0.313 & $<0.001$ \\
\hline & Weekday & -0.457 & 0.199 & 0.022 \\
\hline & Nighttime & 1.484 & 0.246 & $<0.001$ \\
\hline & Adverse weather & 1.563 & 0.260 & $<0.001$ \\
\hline \multicolumn{5}{|l|}{$\beta_{2}$} \\
\hline Driver characteristics & Failure to wear a seatbelt & -1.177 & 0.403 & 0.003 \\
\hline \multirow[t]{4}{*}{ Vehicle attibutes } & Multiple vehicles involved & -0.911 & 0.423 & 0.031 \\
\hline & Overloading & 1.484 & 0.734 & 0.043 \\
\hline & Brake Failure & -1.139 & 0.480 & 0.018 \\
\hline & Disregarding speed limit & 1.673 & 0.578 & 0.004 \\
\hline \multirow[t]{3}{*}{ Road geometrics } & Unsafe following distance & -1.121 & 0.518 & 0.030 \\
\hline & Curve & 1.374 & 0.454 & 0.002 \\
\hline & Downgrade & 1.141 & 0.441 & 0.010 \\
\hline \multirow[t]{5}{*}{ Environmental conditions } & Season & & & \\
\hline & Autumn & 3.053 & 0.758 & $<0.001$ \\
\hline & Winter & 1.418 & 0.464 & 0.002 \\
\hline & Nighttime & 0.909 & 0.427 & 0.033 \\
\hline & Adverse weather & 0.915 & 0.466 & 0.050 \\
\hline \multirow[t]{2}{*}{ a } & $a_{1-2}$ & -2.193 & 0.753 & 0.004 \\
\hline & $a_{2-3}$ & -11.671 & 1.315 & $<0.001$ \\
\hline \multirow[t]{4}{*}{ Fit-of-goodness } & Number of observations & & 1175 & \\
\hline & Log likelihood at zero & & -1141.76 & \\
\hline & Log likelihood at convergence & & -415.37 & \\
\hline & Pseudo $R^{2}$ & & 0.636 & \\
\hline
\end{tabular}


the parallel-lines assumption, and two $\alpha$ coefficients reflecting the cut-off points. Fourteen total explanatory variables, including the age of the driver, seatbelt status, number of vehicles involved, type of transport, conditions of freight, brake system status, disregarding speed limit or not, following distance, horizontal roadway alignment, vertical roadway alignment, seasons, day of week, time of crash, and weather were found to be significantly associated with the truck crash severity. Additionally, 11 variables were found to violate the proportional odds assumption. The average marginal effects of each explanatory variable in the estimated PPO model via the delta-method at the $95 \%$ confidence level were presented in Table 3.

\subsection{Driver characteristics}

Older truck drivers (est. $=0.844, p=0.008$ ) were found to be significantly and positively associated with collision severity (see Table 2). An increase in the injury (2.74\%) and fatality $(3.21 \%)$ probabilities, and a decrease in the PDO probability $(5.94 \%)$ were observed in crashes involving older truck drivers, as shown in Table 3.

On the other hand, truck failure to wear a seatbelt had a significant and positive effect on the collision severity, although it violated the proportional odds assumption. The $\beta_{1}$ and $\beta_{2}$ coefficients for truck drivers who failed to wear seatbelt were 1.664 $(p<0.001)$ and $-1.177(p=$ $0.003)$, respectively. Then, its first panel of coefficient (i.e., PDO vs. injury + fatality) was 1.664 , and the second panel of coefficient (i.e., PDO + injury vs. fatality) was 0.487 . Thus, it can be easily concluded that truck drivers who failed to wear a seatbelt are likely to be involved in more injury crashes. Moreover, according to the marginal effects, the injury probability increased by $9.87 \%$, while the PDO probability decreased by $11.72 \%$, for truck crashes involving drivers not wearing seatbelts.

Table 3 Average pseudo-elasticities for the partial proportional odds model

\begin{tabular}{|c|c|c|c|c|c|c|}
\hline \multirow[t]{2}{*}{ Explanatory variables } & \multicolumn{2}{|l|}{ PDO } & \multicolumn{2}{|l|}{ Injury } & \multicolumn{2}{|c|}{ Fatality } \\
\hline & $\%$ & $p$ & $\%$ & $p$ & $\%$ & $p$ \\
\hline \multicolumn{7}{|l|}{ Driver characteristics } \\
\hline Male & 2.76 & n.s. & -1.27 & n.s. & -1.49 & n.s. \\
\hline \multicolumn{7}{|l|}{ Age } \\
\hline Adult (30 50 years) & -1.03 & n.s. & 0.47 & n.s. & 0.55 & n.s. \\
\hline Old (> 50 years) & -5.94 & 0.008 & 2.74 & 0.014 & 3.21 & 0.008 \\
\hline Failure to wear a seatbelt & -11.72 & $<0.001$ & 9.87 & $<0.001$ & 1.85 & n.s. \\
\hline \multicolumn{7}{|l|}{ Vehicle attributes } \\
\hline Multiple vehicles involved & -6.96 & $<0.001$ & 6.66 & 0.002 & 0.29 & n.s. \\
\hline Commercial transport & 13.53 & $<0.001$ & -6.23 & 0.002 & -7.30 & $<0.001$ \\
\hline Overloading & -14.71 & $<0.001$ & 1.13 & n.s. & 13.58 & $<0.001$ \\
\hline Brake Failure & -4.84 & 0.011 & 6.55 & 0.006 & -1.72 & n.s. \\
\hline Disregarding speed limit & -10.11 & $<0.001$ & -1.70 & n.s. & 11.81 & $<0.001$ \\
\hline Unsafe following distance & -10.09 & $<0.001$ & 8.90 & $<0.001$ & 1.18 & n.s. \\
\hline \multicolumn{7}{|l|}{ Road geometrics } \\
\hline Curve & -4.36 & 0.005 & -3.21 & n.s. & 7.57 & $<0.001$ \\
\hline \multicolumn{7}{|l|}{ Vertical alignment } \\
\hline Upgrade & 4.33 & n.s. & -1.99 & n.s. & -2.34 & n.s. \\
\hline Downgrade & 15.70 & $<0.001$ & -11.56 & $<0.001$ & -4.14 & $<0.001$ \\
\hline \multicolumn{7}{|l|}{ Environmental conditions } \\
\hline \multicolumn{7}{|l|}{ Season } \\
\hline Summer & -10.23 & $<0.001$ & 4.71 & $<0.001$ & 5.52 & $<0.001$ \\
\hline Autumn & 6.80 & 0.020 & -14.73 & $<0.001$ & 7.93 & 0.007 \\
\hline Winter & -11.24 & $<0.001$ & -0.21 & n.s. & 11.45 & $<0.001$ \\
\hline Weekday & 3.22 & 0.021 & -1.48 & 0.030 & -1.74 & 0.022 \\
\hline Nighttime & -10.45 & $<0.001$ & 1.35 & n.s. & 9.09 & $<0.001$ \\
\hline Adverse weather & -11.01 & $<0.001$ & 1.59 & n.s. & 9.41 & $<0.001$ \\
\hline
\end{tabular}




\subsection{Vehicle attributes}

As shown in Table 2, the commercial transport status of the truck (est. $=-1.921, p<0.001$ ) had a significant negative effect on crash severity, which decreased the probabilities of injury and fatality crashes by $6.23 \%$ and $7.30 \%$, respectively, but increased the probability of PDO crashes by $13.53 \%$. Specifically, truck crashes involving multiple vehicles violated the proportional odds assumption. Since the first panel of coefficient (0.988) was larger than the second one (0.077), it was inferred that truck crashes involving multiple vehicles were likely to result in more injuries. In Table 3, a large increase in the injury probability $(6.66 \%)$ and a big decrease in the PDO probability (6.96\%) were observed for these truck crashes.

Truck overloading, brake failure, speeding, and unsafe following distance were found to be significantly and positively correlated with crash severity, but violated the proportional odds assumption. The first panel of coefficients for truck overloading and speeding behaviors was 2.089 and 1.436, respectively, and the corresponding second panel of coefficients was 3.573 and 3.109, respectively, indicating that crashes involving overloaded and speeding trucks were likely to result in more fatalities. As shown in Table 3, truck overloading and speeding behaviors increased the probability of fatality crashes by $13.58 \%$ and $11.81 \%$, respectively, while the probability of PDO crashes was reduced by $14.71 \%$ and $10.11 \%$, respectively. Similarly, the descending series of coefficients showed that brake failure (0.687 vs. -0.452) and unsafe following behavior (1.433 vs. 0.312 ) were likely to result in more injury crashes, which increased the probabilities of injury crashes by $6.55 \%$ and $8.90 \%$, respectively, and reduced the probabilities of PDO crashes by $4.84 \%$ and $10.09 \%$, respectively.

\subsection{Road geometrics}

The results presented in Table 2 reveal that the curve section (est. $=0.619, p=0.006$ ) was significantly and positively correlated with crash severity, which violated the proportional odds assumption. Thus, the first and second panels of coefficient of the variables were 0.619 and 1.993, respectively. Accordingly, it can be easily concluded that trucks at curve sections were likely to be involved in more fatality crashes. The marginal effects in Table 3 show that curve sections were associated with an increase of $7.57 \%$ in the probability of fatality crashes, as well as a decrease of $4.36 \%$ in the probability of PDO crashes.

Moreover, vertical alignment was naturally split into three categories, namely level, upgrade and downgrade, and level was used as the reference category. As expected, the modeling result reveals that there was significant difference between downgrade and level sections (est. $=-2.230, p<0.001$ ), but not between upgrade and level sections (est. $=-0.615, p=0.087$ ). The downgrade section violated the proportional odds assumption. Thus, our results showed that downgrade sections were associated with an increase of $15.70 \%$ in the PDO probability, whereas the injury and fatality probabilities decreased by $11.56 \%$ and $4.14 \%$, respectively.

\subsection{Environment conditions}

Regarding the environment factors, as shown in Table 2, summer season was a fixed parameter that had a significant and positive effect on the probability of truck crash severity (est. $=1.453, p<0.001$ ), which increased the likelihood of injury and fatality crashes by $4.71 \%$ and $5.52 \%$, respectively, and decreased the likelihood of PDO crashes by $10.23 \%$. On the other hand, both autumn and winter violated the assumption, and their ascending series of coefficients ("autumn": - 0.966 vs. 2.087; "winter": 1.596 vs. 3.014 ) showed that truck crashes occurring on an autumn or winter day were likely to result in more fatalities, as shown in Table 3, which considerably changed the probabilities of certain crash severities ("PDO": 6.80\% vs. -11.24\%; "fatality": 7.93\% vs. 11.45\%).

Working days (0:00 Monday to 16:59 Friday) had a significant and negative influence on the truck crash severity (est. $=-0.457, p=0.022$ ), but did not violate the proportional odds assumption, which substantially reduced the chance of injury and fatality crashes by $1.48 \%$ and $1.74 \%$, respectively, and also increased the chance of PDO crashes by $3.22 \%$.

As expected, both the nighttime period and adverse weather conditions violated the proportional odds assumption, and their increasing trend of coefficient panels ('nighttime': 1.484 vs. 2.393; “adverse weather": 1.563 vs. 2.478) indicates that truck crashes occurring during the nighttime period and under adverse weather conditions were likely to result in more fatalities, which increased the likelihood of fatality crashes by 9.09 and 9.41\%, respectively, while the likelihood of PDO crashes was decreased by 10.45 and $11.01 \%$, respectively.

\section{Discussion}

Although Jiangxi and Shaanxi are considered to be distinct rural states, their traffic crashes have similar causes. Particular importance in the current study is the identification of potential contributory factors (i.e., driver characteristics, vehicle attributes, road geometrics, and environment conditions) and the evaluation of their influence on the severity of traffic crashes involving trucks.

The most interesting findings in this study lie in the contributions of the risky driving behaviors of truck drivers to the severity of crashes. Speeding was found to be associated with more fatality crash outcomes in accordance with previous findings $[1,3,5,12-14$, 19]. It 
was clear that excessive speed decreased the ability of truck drivers to react to unexpected road hazards ahead of time, especially under adverse weather conditions or during the period from midnight to dawn, which increased the chance of crashes. These findings may encourage strict law regulations to enforce higher penalties for those drivers disobeying the speed limits.

Also, not keeping a safe distance from other vehicles was found to be significantly related to higher injury and fatality probabilities. This result is consistent with a previous finding in Taiwan [4]. However, this finding is inconsistent with that of other similar studies conducted in Jiangxi and Shaanxi, China [1, 3], which suggested that keeping a safe distance was instead a major cause of truck crashes that correlated with these two freeway segments in mountainous areas rather than a universal issue of regional roadway networks. Noteworthy, failing to wear a seatbelt was related to higher injury probability in line with previous findings $[3,10,13,19]$. However, although seatbelt use significantly reduces the fatality probability in truck crashes, the drivers of heavy trucks are not willing to wear seatbelts [21]. This result also highlighted the need for improving seatbelt use among truck occupants through education programs and installation of a seatbelt warning system that reminds both front seat and rear seat passengers to wear their seatbelts. In addition, laws requiring both front seat and rear seat occupants to use seat belts should be strictly enforced, and those who do not follow this law should receive harsh punishment.

In terms of the effects of driver characteristics, old truck drivers had significantly increased the probability of being involved in injury and fatality crashes. This finding is in good agreement with those of previous reports $[22,23]$. One possible explanation for this result is that the concentration, cognitive ability, and reaction time required for safe driving begin to decrease in truck drivers as they age, making them more likely to be involved in wrecks. However, sex difference was not found to have an influence on the chance of being involved in injury and fatality crashes, which is in accordance with our previous finding [3] and in discordance with the results of other studies $[24,25]$. This may be due to the very low proportion of female truck drivers $(6.30 \%$ of the total sample).

From the perspective of vehicle attributes, the involvement of multiple vehicles in crashes was likely to result in more injury outcomes, which is in line with previous studies $[1,4,9]$. A possible explanation for this result is that the rear-ending of small vehicles (such as passenger cars) by large trucks at high speed often results in severe injury outcomes due to their different structural integrity and size. This result also emphasizes the need for managing the daily transport of heavy, oversize and overweight trucks. The modeling results also showed that the commercial transport trucks are statistically associated with the probabilities of lower injury and fatality, which are not in line with previous findings $[1,3,4]$. A possible explanation for this is that there is not enough variability in the original data due to the obvious low percentage of commercial trucks ( $4.43 \%$ of the total sample).

On the other hand, vehicle overloading and brake failure situations significantly increased the injury and fatality probabilities, respectively, especially under adverse weather conditions. These results are in good accordance with previous local studies $[1,3]$, but in disagreement with the findings of the study in Taiwan [4]. This suggests that vehicle overloading and brake failure may represent major concerns specific for truck safety in mainland China, where drivers should be strictly required to comply with speed and load restrictions and to double-check their brake safety performance, especially before entering long, steep downhill gradients.

Regarding the road geometric effects, a higher probability of fatality crashes was significantly associated with the presence of curve sections, but unexpectedly not related to the grades, which is in contrast with previous studies $[1,3,18]$. A likely explanation is that truck drivers, especially the experienced ones, realized the danger of driving the downgrade sections, and drove more carefully at slower speed. This finding also provides useful information by suggesting how to prevent severe crashes by avoiding minor curves when designing new freeways in mountainous regions. For the existing vertical grades along freeways in mountainous areas, traffic signs and markings are necessary to warn the passing drivers of a steep downhill drive ahead.

With respect to the environment conditions influence, our results also confirmed findings by previous studies indicating that the probability of more serious outcomes of truck crashes increases during the summer and winter days and under adverse weather conditions. This is also consistent with numerous previous studies showing the strong relationship between the season and weather conditions and the crash severity $[1,3,4,10,12,16,19,23$, $26]$. Naturally, the rainy weather condition typically occurs during the days of summer season, while foggy and snowy weather conditions usually occur in the cold months of late autumn and winter within the mountainous areas in China. Thus, the reduced visibility and coefficient of friction between the tire and the road increase the probability of severe crashes. In the summer months, on the other hand, there is a larger number of motor vehicles on the surveyed freeways in the mountainous regions, which increases the exposure of passenger cars and other small-sized vehicles on the mixed traffic flow. Accordingly, the local freeway management department should provisionally lower the speed limits or close 
entrances of freeways in mountainous areas as necessary under adverse weather conditions (i.e., slippery pavement, heavy rain or snow and low visibility).

Additionally, driving during the nighttime period also significantly increased the probability of fatality crashes. One reason for this increase is that commercial truck drivers were driving for longer hours and often at night. As a result, they were generally more susceptible to fatigue and sleepiness, which exhausted them more quickly and made them significantly more prone to be involved in severe crashes as found in our previous studies [3, 27, 28]. From a human perspective, however, truck drivers usually drive more cautiously in dark road conditions [9]. Consequently, the percentage of drivers involved in fatal crashes is often much greater than that in PDO crashes. Laws and regulations should therefore be enacted and strictly enforced to limit the number of fortnightly driving hours and minimum rest hours of truck drivers during the nighttime period, especially for those who engage in long distance commercial transportation, and any offenders should be seriously punished.

\section{Conclusions}

The value of this research is that it examines the influence of potential risk factors on truck crash severity, as well as the marginal effects of each explanatory factor by combining 1175 truck crash samples from two freeway segments in mountainous regions in Jiangxi and Shaanxi, China, and using a PPO model with a logit function. The results showed that overloading was the most important determinant of the severity level of truck crashes occurring within these two geographic regions. The age of the driver, seatbelt use, number of vehicle involved in crash, type of transport, freight conditions, brake system status, disregarding speed limit or not, following distance, horizontal roadway alignment, vertical roadway alignment, seasons, day of week, time of crash, and weather were also found to have marked effects on the level of truck crash severity. These findings can eventually be employed to promote the safe operation of trucks on freeways in mountainous areas in Jiangxi and Shaanxi, China.

However, this study is not without important methodological limitations. First, the crash sample were only selected from two freeway segments in Jiangxi and Shaanxi, China, and may not be representative of the overall traffic safety situation of freeways in mountainous areas in the entire country. Second, the original data may contain some incomplete, and possibly incorrect information or may even be missing some information due to unreported crashes or injuries and errors incurred in manual data entry. Third, the characteristics of the original crash data were not fully considered and thus more potential data processing approaches would facilitate a more comprehensive and in-depth research. It is worth noting that the psychological state of the driver, driving habits, and smart techniques should be integrated into the data analysis and countermeasures suggestions in future research [29-31].

Numerous previous studies reported that truck drivers worldwide are exposed to similarly heavy workload conditions and considerable risk of crashing, especially for those engaged in working night shift and long distance transportation $[1,3,11,26]$. The current findings are in good agreement with those reported in Illinois [13], Alabama [16], Tennessee [18], Colorado [26], and North Dakota [26] in the United States as well as in Egypt [6] and Pakistan [32]. In Belgium, truck drivers were found to suffer from a variety of sleeping problems and sleep disorders, and thus were more likely to get involved in crashes while driving for work [33]. In Norway and France, a higher risk level of accidents involving truck drivers was reported to be significantly associated with psychoactive drug usages [17, 34]. A study from 300 male truck drivers in the Rhône region of France showed that failing to wear an adequate seatbelt was one of the major factors contributing to their particular injury severities in traffic crashes [35]. A simulation result of the A15 corridor in the Netherlands showed that large-scale truck platooning had an obvious impact on traffic flow efficiency and safety [36]. Since there are a large proportion of freeways in mountainous areas in European countries like Germany, Italy, Switzerland, and Luxembourg, the proposed PPO model can thus be used to examine the relationship between driver, vehicle, roadway and environment variables and injury severity of crashes involving large trucks on the mountainous areas of those countries. Evidently, the findings of this study provide important implications for worldwide decision-making in traffic infrastructure design and safety management for truck traffic on freeways in mountainous areas.

\section{Acknowledgements \\ The authors acknowledge the Department of Transport of Jiangxi Province, Jiangxi Research Institute of Communications and Shaanxi Provincial Highway Bureau for providing crash data and cooperation of site visits.}

\section{Funding}

This research is partially supported by the Key Programs of Department of Transport of Shaanxi, China (15-42R).

\section{Availability of data and materials}

The datasets generated and analyzed in the current study are not publicly available due to privacy reasons, but are available from the corresponding author upon reasonable request.

\section{Authors' contributions}

YW designed the study, interpreted results and drafted the manuscript. YL collected the crash data and performed data analysis. FC helped collected the data and contributed to the interpretation of results. All authors have read and given final approval of the version to be published. 


\section{Competing interests}

The authors declare that they have no competing interests.

\section{Publisher's Note}

Springer Nature remains neutral with regard to jurisdictional claims in published maps and institutional affiliations.

\section{Author details}

'School of Highway, Chang'an University, P.O.Box 487, Middle Section of South 2 Ring Rd., Xi'an 710064, Shaanxi, China. ${ }^{2}$ School of Computer and Electronic Information, Guangxi University, 100 East Daxue Rd., Nanning 530004, Guangxi, China.

\section{Received: 28 July 2018 Accepted: 7 May 2019}

Published online: 20 May 2019

\section{References}

1. Chen, C., \& Zhang, J. (2016). Exploring background risk factors for fatigue crashes involving truck drivers on regional roadway networks: A case control study in Jiangxi and Shaanxi, China. SpringerPlus, 5, 582. https://doi. org/10.1186/s40064-016-2261-y (12 pages).

2. Departmsent of Environment, Transport and the Regions. (1998). Accidents Great Britain 1997 - The casualty report. London: Government Statistical Service.

3. Wang, Y., \& Prato, C. G. (2019). Determinants of injury severity for truck crashes on mountain expressways in China: A case-study with a partia proportional odds model. Safety Science, 117, 100-107. https://doi.org/10. 1016/j.ssci.2019.04.011

4. Chu, H. C. (2012). An investigation of the risk factors causing severe injuries in crashes involving gravel trucks. Traffic Injury Prevention, 13(4), 355-363. https://doi.org/10.1080/15389588.2012.654545.

5. Ma, Z., Zhao, W., Chien, S. I., \& Dong, C. (2015). Exploring factors contributing to crash injury severity on rural two-lane highways. Journal of Safety Research, 55, 171-176. https://doi.org/10.1016/j.jsr.2015.09.003.

6. Elshamly, A. F., El-Hakim, R. A., \& Afify, H. A. (2017). Factors affecting accidents risks among truck drivers in Egypt. MATEC Web of Conferences, 124, 04009. https://doi.org/10.1051/matecconf/201712404009 (5 pages).

7. Di Milia, L. (2006). Shift work, sleepiness and long distance driving. Transportation Research Part F: Traffic Psychology and Behaviour, 9(4), 278285. https://doi.org/10.1016/j.trf.2006.01.006.

8. Chen, C., \& Xie, Y. (2014). The impacts of multiple rest-break periods on commercial truck driver's crash risk. Journal of Safety Research, 48, 87-93. https://doi.org/10.1016/j.jsr.2013.12.003.

9. Islam, M., \& Hernandez, S. (2013). Large truck-involved crashes: Exploratory injury severity analysis. Journal of Transportation Engineering, 139(6), 596604. https://doi.org/10.1061/(ASCE)TE.1943-5436.0000539.

10. Chang, L. Y., \& Chien, J. T. (2013). Analysis of driver injury severity in truckinvolved accidents using a non-parametric classification tree model. Safety Science, 51(1), 17-22. https://doi.org/10.1016/j.ssci.2012.06.017.

11. Khorashadi, A., Niemeier, D., Shankar, V., \& Mannering, F. (2005). Differences in rural and urban driver-injury severities in accidents involving large-trucks: An exploratory analysis. Accident Analysis and Prevention, 37(5), 910-921. https://doi.org/10.1016/j.aap.2005.04.009.

12. Lemp, J. D., Kockelman, K. M., \& Unnikrishnan, A. (2011). Analysis of large truck crash severity using heteroskedastic ordered probit models. Accident Analysis and Prevention, 43(1), 370-380. https://doi.org/10.1016/j. aap.2010.09.006

13. Chen, F. \& Chen, S. (2011). Injury severities of truck drivers in single- and multi-vehicle accidents on rural highways. Accident Analysis and Prevention, 43(5), 1677-1688. https://doi.org/10.1016/j.aap.2011.03.026.

14. Peng, Y., Wang, X., Peng, S., Huang, H., Tian, G., \& Jia, H. (2018). Investigation on the injuries of drivers and copilots in rear-end crashes between trucks based on real world accident data in China. Future Generation Computer Systems, 86, 1251-1258. https://doi.org/10.1016/j.future.2017.07.065.

15. Dong, C., Dong, Q., Huang, B., Hu, W., \& Nambisan, S. S. (2017). Estimating factors contributing to frequency and severity of large truck-involved crashes. Journal of Transportation Engineering, Part A: Systems, 143(8), 04017032. https://doi.org/10.1061/JTEPBS.0000060.

16. Islam, S., Jones, S. L., \& Dye, D. (2014). Comprehensive analysis of single- and multi-vehicle large truck at-fault crashes on rural and urban roadways in
Alabama. Accident Analysis and Prevention, 67, 148-158. https://doi.org/10. 1016/j.aap.2014.02.014.

17. Gjerde, H., Normann, P. T., Christophersen, A. S., Samuelsen, S. O., \& Mørland, J. (2011). Alcohol, psychoactive drugs and fatal road traffic accidents in Norway: A case-control study. Accident Analysis and Prevention, 43(3), $1197-$ 1203. https://doi.org/10.1016/j.aap.2010.12.034.

18. Dong, C., Nambisan, S. S., Richards, S. H., \& Ma, Z. (2015). Assessment of the effects of highway geometric design features on the frequency of truck involved crashes using bivariate regression. Transportation Research Part A: Policy and Practice, 75, 30-41. https://doi.org/10.1016/j.tra.2015.03.007.

19. Osman, M., Mishra, S., \& Paleti, R. (2018). Injury severity analysis of commercially-licensed drivers in single-vehicle crashes: Accounting for unobserved heterogeneity and age group differences. Accident Analysis and Prevention, 118, 289-300. https://doi.org/10.1016/j.aap.2018.05.004.

20. Williams, R. (2006). Generalized ordered logit/partial proportional odds models for ordinal dependent variables. Stata Journal, 6(1), 58-82. https:// doi.org/10.1177/1536867X0600600104.

21. Eluru, N., \& Bhat, C. R. (2007). A joint econometric analysis of seat belt use and crash-related injury severity. Accident Analysis and Prevention, 39(5), 1037-1049. https://doi.org/10.1016/j.aap.2007.02.001.

22. Chen, G. X., Amandus, H. E., \& Wu, N. (2014). Occupational fatalities among driver/sales workers and truck drivers in the United States, 2003-2008. American Journal of Industrial Medicine, 57(7), 800-809. https://doi.org/10. 1002/ajim.22320.

23. Isiam, S., Hossain, A. B., \& Barnett, T. E. (2016). Comprehensive injury severity analysis of SUV and pickup truck rollover crashes: Alabama case study. Transportation Research Record, 2601, 1-9. https://doi.org/10.3141/2601-01.

24. Thiese, M. S., Ott, U., Robbins, R., Effiong, A., Murtaugh, M., Lemke, M. R., Deckow-Schaefer, G., Kapellusch, J., Wood, E., Passey, D., Hartenbaum, N., Garg, A., \& Hegmann, K. T. (2015). Factors associated with truck crashes in a large cross section of commercial motor vehicle drivers. Journal of Occupational and Environmental Medicine, 57(10), 1098-1106. https://doi.org/ 10.1097/JOM.0000000000000503

25. Sassi, S., Hakko, H., Raty, E., \& Riipinen, P. (2018). Light motor vehicle collisions with heavy vehicles - psychosocial and health related risk factors of drivers being at-fault for collisions. Forensic Science International, 291, 245-252. https://doi.org/10.1016/j.forsciint.2018.08.037.

26. Zheng, Z., Lu, P., \& Lantz, B. (2018). Commercial truck crash injury severity analysis using gradient boosting data mining model. Journal of Safety Research, 65, 115-124. https://doi.org/10.1016/j.jsr.2018.03.002.

27. Wang, Y., Xin, M., Bai, H., \& Zhao, Y. (2017). Can variations in visual behavior measures be good predictors of driver sleepiness? A real driving test study. Traffic Injury Prevention, 18(2), 132-138. https://doi.org/10.1080/15389588. 2016.1203425

28. Wang, Y., Li, L., \& Prato, C. G. (2019). The relation between working conditions, aberrant driving behaviour and crash propensity among taxi drivers in China. Accident Analysis and Prevention, 126, 17-24. https://doi.org/ 10.1016/j.aap.2018.03.028.

29. Cardamone, A. S., Eboli, L., Forciniti, C., \& Mazzulla, G. (2017). How usual behaviour can affect perceived drivers' psychological state while driving. Transport, 32(1), 13-22. https://doi.org/10.3846/16484142.2015. 1059885.

30. Razi-Ardakani, H., Mahmoudzadeh, A., \& Kermanshah, M. (2018). A nested logit analysis of the influence of distraction on types of vehicle crashes. European Transport Research Review, 10, 44. https://doi.org/10.1186/s12544018-0316-6 (14 pages).

31. Ma, C., Hao, W., Xiang, W., \& Yan, W. (2018). The impact of aggressive driving behavior on driver-injury severity at highway-rail grade Ccrossings accidents. Journal of Advanced Transportation, 2018, 9841498. https://doi. org/10.1155/2018/9841498 (10 pages).

32. Hussain, G., Batool, I., Kanwal, N., \& Abid, M. (2019). The moderating effects of work safety climate on socio-cognitive factors and the risky driving behavior of truck drivers in Pakistan. Transportation Research Part F: Traffic Psychology and Behaviour, 62, 700-715. https://doi.org/10.1016/j.trf.2019.02.017.

33. Braeckman, L., Verpraet, R., Van Risseghem, M., Pevernagie, D., \& De Bacquer, D. (2011). Prevalence and correlates of poor sleep quality and daytime sleepiness in Belgian truck drivers. Chronobiology International, 28(2), 126 134. https://doi.org/10.3109/07420528.2010.540363.

34. Labat, L., Fontaine, B., Delzenne, C., Doublet, A., Marek, M. C., Tellier, D., Tonneau, M., Lhermitte, M., \& Frimat, P. (2008). Prevalence of psychoactive substances in truck drivers in the Nord-Pas-de-Calais region (France). 
Forensic Science International, 174(2-3), 90-94. https://doi.org/10.1016/j. forsciint.2007.03.004.

35. Charbotel, B., Martin, J. L., Gadegbeku, B., \& Chiron, M. (2003). Severity factors for truck drivers' injuries. American Journal of Epidemiology, 158(8), 753-759. https://doi.org/10.1093/aje/kwg200.

36. Yang, D., Kuijpers, A., Dane, G., \& Van der Sande, T. (2019). Impacts of largescale truck platooning on Dutch highways. Transportation Research Procedia, 37, 425-432. https://doi.org/10.1016/j.trpro.2018.12.212.

Submit your manuscript to a SpringerOpen ${ }^{\circ}$ journal and benefit from:

- Convenient online submission

- Rigorous peer review

- Open access: articles freely available online

- High visibility within the field

- Retaining the copyright to your article

Submit your next manuscript at $\boldsymbol{\nabla}$ springeropen.com 